their fears and in my experience will not be used unless necessity requires it. In a few days, when confidence is established, the syringe together with all morphia, will be voluntarily handed to me, and the patient will place himself entirely and unreservedly under my care, willing to assist in the treatment of his case to the utmost of his ability.

Lastly, I would enjoin you to pour out your full sympathy towards the unfortunate opium habituate who has had a hard battle to sum up enough courage to present himself to you for treatment. He needs help. He needs care. He needs kindness. He has suffered long years of torture and deprivation; been tossed hither and thither, like a rudderless vessel, upon the turbulent waves of a cold and austere world; looked upon as a vicious outcast whose every action is treated with suspicion, his statements doubted, his case mismanaged. Give credence to what he tells you. Extend a rescuing hand to the drowning man. Pour oil and wine on his smarting wounds, let your full sympathy and aid go out towards him; you will then brighten a dark spot in the deepest of despair, and have the heartfelt thankfulness of an ever grateful fellow being.

\section{DOES SCIENCE JUSTIFY THE USE OF ALCOHOI, IN THERAPEUTICS? IF SO, WHERE? WHEN? \\ Read before the Section of Medical Jurisprudence and Neurology, a the Forty-second Annual Meeting of the American Medical Association, Washington, D. C., May 6, $189 x$. \\ BY ELISHA CHENERY, M.D., OF BOSTON, MASS.}

The time is upon the profession to review and recast its notions concerning the use of the alcoholic compounds in the treatment of disease, grounded upon what they are, what they do, and what they do not do; for Argus-eyed science of our day shows alcohol to be widely different from what was supposed of it, in the years that are past. If our fathers drove their cows around a stump to make them give down the milk, we are not bound to do the same. Moreover, the liquor treatment has come to have a moral bearing, which both the human and the divine of our profession requires that we respect. And let me here add what the learned President of this Section has said: "The influence and teaching of the medical profession on the great drink question, is most imperatively demanded." Yet I radically differ from him in another statement: "Medically and scientifically, the whole subject is the polar region of mystery."

Certainly this speaks poorly of the candor of those who still prescribe it. If so, then why not leave it alone?

Bunyan got his hero into the Slough of Despond; but does any one in his senses believe that the Slough of Despond is a necessary part of the pilgrim's pathway?

My subject compares to my time, to day, like a man's hat to a boy's head. Hence I can touch only a few points, and that in the most unsatisfactory way-of leaving out most of the proofs of my positions.

\section{ALCOHOL AS A RESTORATIVE.}

This term includes the tonics-agents which increase strength and overcome languor-the promoters of the constructive metamorphoses, and the force producers. It excludes that which adds nothing, only whips out the strength the body already has. Restoratives are in great demand. The physician to-day prescribes them more frequently than any, if not all, others. $\mathrm{He}$ feels, when doing so, he is adding to the sum total of vitality.

Considering alcohol in this relation, we meet the fact that its chemistry is squarely against it. Not a particle is incorporated into the bodily tissues; so, to say the least, he is visionary in the extreme who prescribes it with the idea that it is incorporated, or that it incorporates anything else.

It contains carbon, as all carbo-hydrate food substances do; but that carbon cannot be extracted from it as from them. They all undergo certain changes, as chemistry shows; while it enters, pervades, and escapes from the body as alcohol, no proof of its transformation, either in the digestive tract, the blood or the tissues, ever having been found. This one fact of its indigestibility nullifies all arguments in its behalf as a force producer. If any contend that it does change, let them give the evidence.

The various symptoms, commonly attributed to this supposed change, are very satisfactorily accounted for from its known irritating and anæsthetic actions. Yet if we admitted all that has been claimed for it in this respect, we concede very little, for Voit and Subbotin say: "In the amount we can take without injury, its importance as a nutriment is too small to be considered." But we have no warrant for the concession.

That all the liquor taken cannot be recovered, we allow. It is the same when alcohol is mingled directly with freshly drawn blood: But the mere loss of a portion is not a proof that that portion changes and becomes useful. Such conclusion is not scientific nor rational. The loss of my knife is not proof that Jones has it, or that he stole it. As well contend that Stanley's "rear column" found Emin Bey. Better do as Hahnemann did-jump from the tangible of medicines into their spirituality. Right reason requires that we withhold our conclusions till we establish the premises. In the light of the foregoing, how unreasonable were the assumptions 
of Dr Todd: "Alcohol is the most easily digestible and assimilable of substances. . . . It oxidizes in place of the tissues." Equally absurd is the theory that alcohol conserves tissue, as we showed in our essay last year. ${ }^{1}$

That it is sustaining because some persons have lived a long time while taking it, is not conclusive. There is every reason to believe they would have done better without it. Had Dr. Tanner and the others who fasted longer than he, depended on alcohol rather than on the store of nourishment in their bodies with water to dissolve it, it is unquestionable that the undertaker would have had them long ere the forty or fortyfive days expired. But, so far from acting as a restorative, abundant, careful observation shows that liquor actually depreciates the strength one has. It is the strong, not the weak, who bear it -not the young, the feeble, and those addicted to it. In other words, the strong can resist it, while the weak cannot.

Thus speaks Dr. Chambers: "Above all, I would caution against employing wine as a substitute for the true restorative treatment." "To call alcohol food," writes the Editor of the British Medical Journal, "in the present state of our knowledge, is an abuse of language." "The popular belief," says Dr. A. Mullan, "that beer and other alcoholic drinks are strengthening, is a mistake, a delusion, a mere superstition, which receives no support from science."

\section{Al.COHOL AS A STIMULANT.}

This class adds little or nothing to the bodily forces. They call out what was in store, using it up before its time. They act promptly, and for the time only. Their repetition is a matter of much discretion. They take from the sum total of vitality, and lead to exhaustion unless wisely guarded. Alcohol has so monopolized this term, that alcoholics and stimulants are at present quite synonymous. But is not the term mostly nisapplied when applied to alcohol ? When and where does it summon out the forces of the body the better to resist opposing forces? Never, except in very small doses, much smaller than we should be likely to give, if we give it with the idea that it is stimulating.

If we, for a moment, lay aside our pack of vague notions, and sit down at the deliverance of instruments of precision, we shall learn for certainty that any considerable doses do not stimulate, but depress and weaken. "Careful observations," Brinton states, "leave little doubt that a moderate dose of beer or wine will, in most cases, diminish the maximum weight a person can lift." So Liebig: "The circulation will appear accelerated at the expense of the force

" "Does Alcohol Conserve 'Tissue?" in pamphlet. Free to physicians who send to the author for it. See this much more full shown in the author's "Alcohol Inside Out," I 2mo, 350 pages, mail ed for $\$ I$. available for voluntary motion, but without the production of a greater amount of mechanical force. It is attended with an inward loss of power." Prof. Marvaud of France, Zimmerherg of Germany, Richardson of England, and Martin of Baltimore, have wrought at this and find alike. According to Prof. Martin, as much as an ounce of whisky or brandy always lessens the force of the heart, though generally increasing its frequency. Prof. W. E. Ground, of Toledo, asserts "that it acts as a paralyzer from the first, through paralytic effect on the nerve centres, as in experiments where the inhibitory nerve is cut." Alcohol adds no heat. It strengthens neither body or mind; and this is not only science, but the common sense view of common experience. Alcohol agitates the system, while nutritive agents perform their work silently within, leaving other functions undisturbed. Moreover, it has certain drawbacks which stand in the way of its repetition, which proper stimulants do not have. Cold, or mechanical irritation to the stomach, increases heart frequency, and heart and vascular force. For the instant, small doses of spirits will do this, but, directly after, the absorbed portion begins to paralyze the nerves and capillaries. Hence heat, hot drinks, the aromatics, etc., are the proper means to warm a chilled person. They do not tumble the blood into the external capillaries as alcohol does, to the neglect of the more important internal parts. Whales are made to resist cold and not heat. Their exterior is in contact with the waters of the polar seas, while under their skins is a thick layer of non-conducting blubber, beneath which their warm blood circulates. Our bodies are made to resist both heat and cold. Exposed to the latter, perspiration stops, the skin contracts, forcing most of the blood beneath the subcutaneous layer of fat, where its heat is protected. A drink of grog unlocks the skin and drives the blood to the surface, dissipating its heat, just as would happen to the whale if his blood were brought to the outside of his blubber, when it would lose temperature and his heart chill. Not only is alcohol bad in this way, but it does more; it puts a wet blanket over the internal fires, by shrinking and depressing the functions of the blood cells. So, so far from its being a stimulant to bring out the forces of the system to resist cold, it is a traitor, and appears doubly armed on the side of the enemy. Arnold had his good qualities; so has this. If a person has been exposed to severe cold, and is suffering internal pains and cramps from the vascular engorgement, no doubt alcohol has temporary helpful relations to the case, bringing the blood away to the surface. So has it useful relations to syncope, to shock, and to other cases of deficient brain circulation, where its irritation to the stomach, and not its absorption, may serve. Hence, 
what is used for the purpose should be strong. There are many other things as good, if not better. Thus the horizontal position, splashing the face and neck with cold water, cold or hot drinks, aromatic teas, camphor, ammonia, are appropriate, and are the people's remedies; while physicians may add amyl-nitrate, nitro-glycerine, and other things too numerous to mention. For years, nitro-glycerine has been the chief remedy of the writer. It is good to administer in anticipation of faintness from operations. So iron, and not alcohol, for anæmia and anæmic neuralgia; bismuth for gastralgia and pyrosis; not whisky, but the bromides, capsicum, digitalis, feeding, nutritious enemata, for delirium tremens; heat to the chest, camphor, ammonia, strophanthus, digitalis for the flagging heart; not alcohol, but digitalis, strychnia for dropsy ; camphor, chloroform, turpentine, not liquor, for malarial chills ; not liquor, but turpentine, ergot, salt, milk, for hæmorrhages; not alcohol in congestive dysmenorrhœa, inflammatory colic, dysentery, and a thousand other conditions in which stimulation is required. [In all cases of nervous exhaustion, or where the stomach is at fault, Dr. Archibald Billings says "restoration will not be expedited by stimulants," meaning alcoholics. Being, then, rather a hindrance than a help, good sense is on the side of the surgeons of certain corporations where accidents are common, in recommending that the employés be prohibited from resorting to liquor in cases of injury.]

\section{ALCOHOL AS AN ANASTHETIC.}

It would be well if this term, as applied to alcohol, were excluded from medicine. That alcohol by the skin, stomach, lungs, obtunds the nerves, paralyzes the muscles, stupefies the brain, needs no confirmation here. As persons see these effects, they name it according to their concep. tions-intoxicant, narcotic, paralyzant, etc. I use the word anæsthetic, for, like Aaron's rod, it swallows up all the rest.

Anæsthesia is the most conspicuous of its effects. It is this which balms the feelings and brings the cheer; that smothers the aches and the pains; that exbilarates the mind, beguiles to repetition, to increasing doses, to habit, to inebriety, upsetting the mind, and raising the devil.

Alcohol is thus the very mad dog of materia medica. Nevertheless, it was the best anæsthet ic known to our fathers. They also wore wooden shoes, things we need not wear. Ether, gas, chloroform, and many other agents have come to the fore, pushing it to the rear. They are not so deceptive, so seductive, so habit-producing, and those who handle them are not so likely to catch the Tartar-inebriety.

Having so numerous and efficient agents as substitutes, agents which have not its peculiar back-cut upon the blood cells, I need not waste time in pointing out when and where it can be used in this direction; for it was the new cane the old man used while all the former ones were put in a brace in the wood shed. Neither need I stop to indicate the purposes its varied properties fit it to serve as an external remedy. I therefore pass at once to my last point.

\section{ALCOHOL AS A PERTURBATOR OF THE ORGANISM.}

The effects of alcohol on structure, and so, on functions, marks it as the most remarkable disturber of the animal body with which we are acquainted. Whatever else it may do, here it takes preëminence. Its etherial influence, to be sure, are the lulling wings of the vampire; in this is its mouth applied to the vital fluids. Its anæsthesia is the dummy hand of the thief; here are the concealed fingers which filch the purse. The mental exhilaration it produces is the smiling face of Brutus; this, his bloody hand which plunges the poniard.

With all that is known of the morbid changes produced by alcohol, how little is systematically considered and applied in practice? Last year I called attention to its power over the blood corpuscles, and showed a photograph of the extreme changes it produces in their physical character, in a portion of blood taken directly from a drunken man. This was right to the point. It gave ground for explanations and deductions otherwise impossible. Knowing the physiology of these corpuscles, as the gas carriers of the body, we do not require to be beaten with a club to comprehend that such alteration in their character must amazingly effect their important functions. But this is not all. The alcohol which gets into the interior of the corpuscles, acts the part of the $\mathrm{dog}$ in the crib and refuses the oxygen and the carbonic acid. Thus in a double sense their functions are depressed. In the paper referred to, I explained how it was that alcohol so affected their physicalcharacter, by showing that the spirit, having a great attraction for water and little or none for the substance of animal membrane as such, by the laws governing osmotic action, compels the water to come out of the cells and mingle with it on the outside. Not only does it thus collapse the cells, but it also similarly af. fects all other moist structure throughout the body. Who has not seen this in mucus, in albumen, in the protoplasm of rapidly healing wounds?

What it does under the eyes on the outside of the body, it does on the inside, and the more so in proportion, as they are watery and the cell walls delicate. In this way are the tendons, the muscles, the nerves, the connective tissue and the organs affected. Is there, therefore, difficulty in comprehending why the bodies of drinking young men grow old apace? An agent that will steril- 
ize the cells of a pup and prevent their evolution, thus holding his body throughout in the condition of a Chinese woman's foot, must and does pervert the structures of those who drink it. Here, then, we have the key to the alcoholic pathology - the changes so conspicuous in the bodies of old topers, and so surprisingly numerous in the bodies of moderate drinkers suddenly cut off by other causes. This shows why we cannot cure persons made sick by alcohol while the habit is continued; why surgical cases act badly in alcoholized patients; why the healing of wounds is not expedited but hindered when liquor is given; why the white blood-cells are crippled and protoplasmic movements arrested by this agent.

Here is the key that unlocks the mystery of fatty degeneration, fatty bloating. Is it strange that such organs as the kidneys, the liver, the stomach, the brain and spinal cord, the vascular system, should undergo fibroid and cirrhotic changes by so active an agent and acting in the way that alcohol does?

Here is the explanation why the bodily temperature can never be raised by alcohol, but always lowered; and why this antipyritic action cannot be rendered serviceable in practice. Here is its philosophy in weakening brawn and brain. Every other function must be depressed when the blood cells are strangled.

Now, I ask, what reason have we to expect good from it in the treatment of any or all diseases of the respiratory system? They obstruct oxigenation and the elimination of carbonic acid. Does not alcohol do the same? They weaken; this, more. If pneumonia blocks pulmonary circulation and æration, and by heaping excessive labor on the heart, tends to overwork it and ex. haust it, determining heart failure; this, more. Strange that we should lose our heads as philosophers in the face of alcohol. Would that we return to the lancet for this grave disease, relieving the volume of blood upon which the embarrassed heart has to act, and be done with this most irrational and fatal treatment of it, ever employed. If the structural changes in the lungs of consump. tives hinders oxidation and weakens the body, does not liquor do the same, albeit it diminishes the cough by times? Is our philosophy correct when we give alcohol in disintegration with defective depuration, as in fevers and the like? Does it not itself increase depuration by hindering the absorption of oxygen and the expulsion of the waste, represented by carbonic acid and urea?

Certainly if it can obstruct the waste in a well man till he stinks from head to foot, it can never purify the blood of one already foul. These questions, with scores more that might be asked, being based on solid grounds, leave me little room to answer, Where? When? Give alcohol? There is nothing in physiology more certainly scientifi- cally demonstrable than that alcohol changes the structure of the blood-cells, and, through these, the functions dependent upon them, and as their functions are vital and no hindrances to them can conduce to the restoration of the sick, the reasons for alcoholic medication are driven to the polar region of barrenness. They cut the tap-root of the popular liquor therapeutics, and no human invention can make it again bear green leaves. Alcohol, when in any degree of concentration, is opposed to ptyaline, to pepsine, to pancreatine. It is contra-indicated in bilious cases, cirrhosis of the liver, gout, Bright's disease and diabetis; the last of which it can di. rectly produce.

But this paper is not written in ignorance of the fact that many good physicians use it. Were it not that many do, the statements herein would not be worth the making. I may be wrong; we all err. In a neighboring city an astute physician stood up in a medical meeting and deposed in favor of a certain pill, relating numerous cases where he had given it with good results. Another physician followed, showing the same pills which had been gathered from the former's patients, they passing whole, only losing their sugar coats. A prominent member of this Association had a fever case which got into the ty phoid state; his kidneys being obstructed, I counselled efforts to open up the kidneys and skin and so relieve the nervous condition. The doctor was obstinate, believing in "bridging the chasm" with" "the bridge that brandy makes," and gave it. His bridge was rotten. I now have a patient under my care who told me he had taken quite half a barrel of different liquors on the prescriptions of this same physician, and began to improve the moment he left the liquors off. A clergyman called on me, relating that his child had been sick with the typhoid and got to that condition where the doctor said nothing but brandy would save him, and accordingly brought a bottle of it to the house. The clergyman took it, threw it into the back yard, made a liberal portion of beef tea and gave it. Soon the sweat started, and the child fell into a sweet sleep and was better the next morning. The doctor spoke of the change and attributed it to the wonderful power of the spirit. I warmed that clergyman for not unde. ceiving his doctor, and allowing him to go away, strengthened by the success of the brandy in this case, to give it with increased confidence.

It may have been good in cases of fever, diphtheria, etc., where large doses have been given and which appeared to be beneficial. If so, I am very positive that it was owing to its power over the peculiar microbes in these diseases, sterilizing and rendering them inert; for we know that alcohol, at fifteen or twenty per cent. strength, overcomes and practically destroys most of the germs about us, even the blood-cells 
themselves, as I have witnessed, producing death. And it is a most wonderful provision of nature against fatality from the drink habit, that the medulla oblongata is so much more resisting to tha power of alcohol than the rest of the body, continuing its functions when all else is practically dead, keeping the heart beating and the lungs moving, fanning out the poison from the prostrated blood-cells. Were it not so, how of ten would the undertaker's service be required to what it now is!

I know I cannot answer all your questions, yet I trust I have said enough to show you that this subject is not all a mystery, but full of interest and instruction, if we but come out of the clouds and study it from ground principles.

came up the historic Potomac, and, though the oar, the sail, the smoking steamer, seemed to in dicate that the current was devious, I am sure its steady flow is to the ocean beyond. Though I note some drift-wood held in sluggish side currents, some cross currents, whirlpools and waves, I am as satisfied that the stream of alcohol, whether taken foolishly, from habit, or on the advice of physicians, in large or in small doses, has but one general course, one end-the fathomless deep.

Comparing the results of my practice with the practice of those who use it, until something more scientific in its favor comes up, some new revelation is made, the day is far distant when I shall send another Brutus after my Cæsars.

\section{INSANITY AS RELATED TO CIVILIZA- TION. \\ Read before the Section of Medical Jurisprudence, Washington Meet- ing A mercan Medical Association, May, 189t. \\ BY ORPHEUS EVERTS, M.D. \\ SUPERINTENDENT OF THF CINCINNATI SANITARIUM, ETC., COL- LEGE HILL, OHIO.}

Insanity may not be, as is so commonly and confidently asserted, "a disease of civilization" - but conditions essential to the phenomenal manifestations of insanity obtain so rarely among savages and lower animals, and so frequently among civilized people, that, in the absence of contradictory testimony, the assumption that it is so, would seem to be justified. The question then becomes pertinent and interesting: What constitutional modifications are effected by, or with, the process of civilization, whereby human beings are rendered more liable to become insane? Who shall answer?

By common consent the medical profession is looked to for intelligent answers to all questions pertaining to insanity, and the insane. Is the profession qualified to so answer?

Qualified or not, there are members of the profession ever ready to respond; the least qualified, often, being the readiest. Capability to talk volubly, or write voluminously, about insanity -or any other subject, for that matter-with an affectation of learning, is a "gift" not unknown to the profession, however reputable it may be, as a body, for its thoughtfulness and reticence. Such 'gifted' members are, as a rule, however, not the most trustworthy, as expounders of principles, or historians of facts.

By interrogating less pretentious, but ordinarily intelligent members of the profession, respecting the relation of insanity to civilization, it will be found that various opinions are entertained by them on the subject; each having some value when properly estimated; but based upon foundations of facts too narrow and incongruous to stand the test of rational criticism.

Nor should it be anticipated of such men, whose preliminary studies, and subsequent habits of thought and observation have been in the way of specializations, rather than generalizations, should grasp the question as propounded, comprehensively; or respond to it otherwise than by some more or less dogmatic assertion of personal opinion; citing this, that or the other disease, habit, accident, or incident, of civilization, as the true cause of insanity; overlooking the fact that certain physical conditions, tot common to the race, but essential to the manifestation of the phenomena of insanity, must have obtained, individually, before such "causes" could become operative; regardless of all other circumstances.

The first man, for example, will assert, as an indisputable proposition, thatjalcoholic intemperance is the cause, direct or indirect, of all manifestations of insanity!

"The demon alcohol" as this man sees it, has superseded all old fashioned "demons" of whatever genus, or species, to whose machinations all diseases, and death itself (when not inflicted by a supremely good spirit), were attributed by our, not very remote, ancestors; and should now be held responsible, in their stead, for all the misery of mankind.

Nor is this man alone in his belief. A good man, and true, within his own bounds-devoting all the energies of being to an ameliorating of the more painful conditions of his fellow-men-his notions are not singular; nor is his conduct peculiar to himself.

Limited and faratical by nature; cramped by long service in a narrow field of labor; feeling voluminously, but thinking neither comprehensively nor rationally; toiling ever in the penumbra, if not the shadow, of superstition; habitually personifying phenomena, and ascribing general conditions to special antecedents as causes; having witnessed with increasing dismay, from year to year-in his professional as well as his civil capacity - the unstayed ravages of this apparently pitiless and unsparing monster-invading every land and every household-insidious 